\title{
ESTUDIO PRELIMINAR SOBRE EL POTENCIAL DE SUSTITUCIÓN DE ALIMENTO BALANCEADO POR PELLETS DE Stylosanthes multilinea EN EQUINOS
}

\author{
Ana Elena Soto-Morales ${ }^{1}$, Augusto Rojas-Bourrillon ${ }^{2}$
}

\section{RESUMEN}

El Stylosanthes es una leguminosa tropical que se puede someter al procedimiento de peletizado lo que facilita su inclusión como forraje en las dietas de caballos. En la presente investigación se estudió el efecto de la sustitución de alimento balanceado por pellets de Stylosanthes sobre la digestibilidad de la ración. El estudio fue realizado con 4 caballos adultos, capones de la raza Pura Sangre Inglés, con edades entre los 7 y 15 años y con un peso vivo promedio de $521 \mathrm{~kg}$ (desviación estándar=14,53 kg). Los equinos fueron sometidos a una prueba de sustitución del alimento balanceado (consumo máximo de 2 kg/día) por pellets de Stylosanthes en niveles crecientes de 0; $15 ; 30$ y 45\% en base seca mediante un diseño de cuadrado latino simple (4X4). La digestibilidad de la materia seca de la ración total fue en promedio de 64,66; 61,77; 62,99 y 64,26\% para los tratamientos $0 ; 15 ; 30$ y $45 \%$, sin presentar diferencias significativas $(p>0,05)$ entre los tratamientos, animales, ni periodos evaluados. La digestibilidad de la proteína cruda fue 68,$88 ; 65,66 ; 66,94$ y 69,57\% para los respectivos tratamientos, sin diferencias significativas. La digestibilidad promedio de la fibra neutro detergente, fue de 46,46; 48,17; $43,46 \%$ y $46,47 \%$ para los tratamientos de 0; $15 ; 30$ y $45 \%$, respectivamente mostrando diferencias significativas únicamente entre los periodos $(p \leq 0,0097)$. La digestibilidad promedio de la fibra ácido detergente fue 33,06; 35,51; 32,57 y 35,8\% para los 4 tratamientos, mostrando el efecto animal ser significativo $(p \leq 0,013)$ y el periodo altamente significativo ( $p \leq 0,0001)$, respectivamente. La digestibilidad promedio del extracto etéreo fue de 69,$54 ; 82,80 ; 78,76$ y $83,67 \%$ para los tratamientos $0 ; 15 ; 30$ y $45 \%$, sin diferencias significativas entre los tratamientos, animal y periodo. La sustitución del 15; 30 y 45\% de

\footnotetext{
${ }^{1}$ Consultora privada y Gerente General Ecuestre Los Alpes. Autor para correspondencia: sotoanaelena@gmail.com

${ }^{2}$ Universidad de Costa Rica. Centro de Investigación en Nutrición Animal y Escuela de Zootecnia, San José, Costa Rica

Recibido: 18 febrero 2016 Aceptado: 30 de marzo 2016
} 
alimento balanceado por pellets de Stylosanthes representó una disminución del 3,4; 6,9 y $10,3 \%$ del costo de la ración diaria, respectivamente.

Palabras clave: peletización, digestibilidad aparente, nutrición equina, leguminosas tropicales, Stylosanthes multilinea

\section{ABSTRACT}

\section{Preliminary study of potential substitution of feed for Stylosanthes multilinea pellets}

in equines. Stylosanthes is a tropical legume that can be turned into a pellet and included in horse diets. This research studied the substitution of commercial feed by Stylosanthes pellets in the overall ration digestibility of horse diets. The study was made with 4 thoroughbred geldings, with ages between 7 and 15 years. Their average body weight was $521 \mathrm{~kg}(\mathrm{SD}=14.53 \mathrm{~kg}$ ). The horses' diets were increasingly substituted by the Stylosanthes pellets on four different levels $(0 ; 15 ; 30$ and $45 \%$ of the dry matter, and up to $2 \mathrm{~kg} /$ day of intake as fed). The average dry matter digestibility of the ration was 64.66; $61.77 ; 62.99$ and $64.26 \%$ for the treatments $0 ; 15 ; 30$ and $45 \%$, respectively, and did not present significant differences $(p>0.05)$ between treatments, animals or periods. The average crude protein digestibility was 68.88; 65.66; 66.94 y $69.57 \%$ for the four treatments and no significant differences were found. The digestibility for neutral detergent fiber was $46.46 ; 48.17 ; 43.46 \%$ and $46.47 \%$ for the treatments $0 ; 15 ; 30$ and $45 \%$, respectively, and there were significant differences between periods ( $p \leq 0.0097)$. The average acid detergent fiber digestibility was 33.06 ; $35.51 ; 32.57$, and $35.80 \%$ for the treatments and showed significant effects for the animals $(p \leq 0.013)$ and periods ( $p \leq 0.0001$ ). The ether extract digestibility was $69.54 ; 82.80 ; 78.76$ and $83.67 \%$ for the treatments $0 ; 15 ; 30$ and 45\%, and did not show significant differences between treatments, animals or periods. The substitution on 15; 30 and $45 \%$ of the feed by Stylosanthes pellets represented a decrease of $3.4 ; 6.9$ and $10.3 \%$ of the daily cost of the diet.

Keywords: pelletization, apparent digestibility, equine nutrition, tropical legumes, Stylosanthes multilinea 


\section{INTRODUCCIÓN}

Los caballos han sufrido variaciones en sus hábitos de consumo y en las formas de obtención de alimentos debido a cambios en el manejo a los que se han visto sometidos a través del tiempo. En sistemas estabulados, los caballos ven limitado su tiempo de pastoreo y, por tanto, los alimentos a los cuales tienen acceso. Debido a esto, es de suma importancia garantizar la cantidad y calidad óptima de alimentos que permitan satisfacer sus requerimientos nutricionales de acuerdo a su condición corporal y nivel de trabajo realizado (NRC, 2007).

Mediante estudios de digestibilidad de materias primas con potencial de inclusión en dietas de caballos, se puede determinar si existe un aporte benéfico al organismo o, si más bien puede causar problemas. Otro factor de importancia a considerar en el uso de materias primas, es la aceptación individual de las mismas, ya que de no ser así, su potencial se verá disminuido, pues el hecho de proveer a los caballos un alimento de alto valor nutricional no implica que su utilización metabólica sea igualmente favorable (Lawrence, 1995).

Ante la necesidad de nuevas materias primas para ser incluidas en las dietas para caballos, se ha recurrido al uso de leguminosas como la alfalfa en zonas templadas, en donde su producción se da con buenos rendimientos y resultados para el consumo animal. En el caso de los países tropicales, se cuenta con otras leguminosas, como es el caso del género Stylosanthes, cuyo contenido proteico y digestibilidad se reporta superior al de las gramíneas tropicales (Teixeira et al., 2010).

Esta leguminosa pertenece a la familia Fabaceae, subfamilia Faboideae, tribu Aeschynomeneae, subtribu Stylosanthinae (Cook et al., 2005). Existen gran cantidad de variedades de Stylosanthes, sin embargo dependiendo de las características agronómicas y productivas que se busquen así se selecciona cuál de ellas utilizar.

Además de las variedades ya mencionadas, se cuentan con cruces entre ellas, tal es el caso del Stylosanthes multilinea, el cual, según Veizaga et al., (2010), es el producto de la mezcla física de dos especies mejoradas, el Stylosanthes capitata (80\%) x Stylosanthes macrocephala (20\%). A dicho cruce se le conoce comúnmente como Campo Grande. 
Esta leguminosa fue liberada en el año 2000, presenta un ciclo vegetativo perenne y su cosecha puede realizarse por medio del pastoreo, o bien con corte y acarreo. Esta leguminosa puede producirse bajo condiciones de suelos arenosos y de baja fertilidad, mostrando un crecimiento más horizontal, con hojas puntiagudas e inflorescencias principalmente amarillas; puede alcanzar hasta un metro de altura y su floración se lleva a cabo en condiciones normales de abril a mayo. Al igual que las demás leguminosas, cuentan con características deseables para su producción como lo es su alto valor proteico (19\% PC) y su función como fijadora de nitrógeno de la atmósfera en el suelo (20 hasta $200 \mathrm{~kg} \mathrm{~N} / \mathrm{ha} / \mathrm{año}$ ), con lo cual se reducen los insumos agrícolas, contribuyendo a la reducción de agroquímicos e impacto ambiental (Vallis y Gardener, 1984., EMBRAPA, 2000).

Otras cualidades deseables del género Stylosanthes son el alto rendimiento de semilla, la alta capacidad de siembra natural, una buena asociación con ciertas especies del género Brachiaria, como es el caso de Brachiaria decumbens, buena tolerancia al pastoreo y al medio ambiente. Presenta una digestibilidad satisfactoria, al igual que su palatabilidad. Requiere de 900 milímetros por año de precipitación, produciendo 17 toneladas de materia seca por hectárea por año. Además presenta una tolerancia adecuada a insectos y plagas (EMBRAPA, 2000).

Con base en las características agronómicas, nutricionales y al potencial de mecanización e industrialización, es que el Stylosanthes puede ser utilizado como una alternativa alimenticia en el trópico tanto para rumiantes como para caballos. Por lo tanto el objetivo de la presente investigación fue determinar la palatabilidad, consumo y digestibilidad de pellets de Stylosanthes en caballos.

\section{MATERIALES Y MÉTODOS}

El estudio se llevó a cabo en una caballeriza localizada en Los Alpes de San Isidro de Coronado, San José a una altitud de 1536 msnm (latitud 958' Norte, longitud 8359' Oeste). Se utilizó 4 caballos de la raza Pura Sangre Inglés (Cuadro 1), con edades entre los 7 y 15 años y pesos corporales estimados entre 507 y 535 kilogramos. 
Cuadro 1. Características de los caballos utilizados en el estudio.

\begin{tabular}{cccc}
\hline Caballo & Sexo & Edad (años) & Peso (kg) \\
\hline 1 & Macho & 7,00 & 535,00 \\
2 & Macho & 13,00 & 532,00 \\
3 & Macho & 15,00 & 510,00 \\
4 & Macho & 15,00 & 507,00 \\
Promedio & & 12,50 & 521,00 \\
DE $^{*}$ & & 3,78 & 14,53
\end{tabular}

${ }^{*} \mathrm{DE}=$ Desviación Estándar

Los caballos recibieron dietas individuales de acuerdo al peso y trabajo realizado durante el estudio y se mantuvieron estabulados brindándoles una ración de alimento balanceado Corcel de la marca Dos Pinos® (Cuadro 2).

Cuadro 2. Composición nutricional del alimento balanceado Corcel@ suministrado a los equinos.

\begin{tabular}{lc}
\hline Nutriente $^{*}$ & Contenido \\
\hline Energía Digestible (kcal/kg) & 3000,00 \\
Humedad (\%) & 13,00 \\
PC (\%) & 14,00 \\
EE (\%) & 3,00 \\
FC (\%) & 10,00 \\
Calcio (mínimo) (\%) & 0,80 \\
Calcio (\%) & 1,00 \\
Fósforo (\%) & 0,40 \\
Sal (mínimo) (\%) & 0,50 \\
Sal (máximo) (\%) & 1,00 \\
CNF (\%) & 52,00 \\
\hline \multicolumn{2}{c}{${ }^{*}$ Fuente: Laboratorio de ASEG de Calidad, Dos Pinos }
\end{tabular}


El suministro de alimento balanceado se estandarizó en $2 \mathrm{~kg}$.animal'día tal como ofrecido y se fraccionó en dos momentos (mañana 5:30 a.m. y tarde 3:00 p.m.). Los caballos consumieron pasto Estrella Africana (Cynodon nlemfluensis), de corte con una edad de cosecha entre 80 y 90 días (Cuadro 3) en raciones desde los 12 hasta los 16 kilogramos diarios (tal como ofrecidos). A partir de dichos alimentos, los caballos satisfacen sus requerimientos de mantenimiento promedio de acuerdo al NRC (2007).

Cuadro 3. Composición nutricional del forraje Estrella Africana (Cynodon nlemfluensis) suministrado a los equinos.

\begin{tabular}{lc}
\hline Nutriente $^{\star}$ & Contenido \\
\hline MS (\%) & 30,40 \\
PC (\%) & 9,17 \\
FDA (\%) & 40,80 \\
FND (\%) & 68,61 \\
EE (\%) & 1,84 \\
Cenizas (\%) & 9,62 \\
Lignina (\%) & 5,16 \\
CNF (\%) & 10,77 \\
Hemicelulosa (\%) & 27,82 \\
ED (kcal/kg MS) & 2120,76 \\
\hline
\end{tabular}

${ }^{*}$ Fuente: Laboratorio de ASEG de Calidad, Dos Pinos

**De acuerdo a Pagan (1994), citado por Pulido et al. 2003)

Se llevó a cabo una aleatorización para asignar los cuatro caballos a los tratamientos, los cuales consistieron en niveles crecientes de sustitución del concentrado comercial en valores de 0 (control), 15, 30 y 45\% en base seca por pellets de Stylosanthes (Cuadro 4). Cada uno de los caballos fue sometido a los diferentes niveles de sustitución para establecer el efecto en cada uno de acuerdo al diseño establecido, por lo que el diseño experimental consistió en un Cuadrado Latino Simple (4x4).

Previo al inicio del experimento, los caballos fueron expuestos al consumo de los pellets de Stylosanthes en cantidades inferiores a los tratamientos a evaluar con el objetivo de descartar rechazo por parte de los equinos. Los caballos se sometieron a 9 días de acostumbramiento a cada nivel de sustitución con los pellets de Stylosanthes y 5 días de muestreo de las heces para cuantificar el marcador de digestibilidad y estimar su producción. Las heces se muestrearon cada 4 horas para posteriormente elaborar 
muestras compuestas para los análisis del marcador (cenizas insolubles en ácido) y la composición nutricional de las mismas.

Cuadro 4. Composición nutricional de los pellets de Stylosanthes multilinea proporcionados a los equinos.

\begin{tabular}{lc}
\hline Nutriente $^{*}$ & Contenido \\
\hline MS (\%) & 88,26 \\
PC (\%) & 17,94 \\
FAD (\%) & 36,21 \\
FND (\%) & 44,60 \\
EE (\%) & 1,94 \\
Cenizas (\%) & 12,08 \\
Lignina (\%) & 5,23 \\
CNF (\%) & 23,43 \\
Hemicelulosa (\%) & 8,39 \\
ED (Kcal/Kg MS) & 2235,24 \\
*Fuente: Laboratorio de ASEG de Calidad, Dos Pinos \\
**De acuerdo a Pagan (1994 citado por Pulido et al. 2003)
\end{tabular}

Para evitar variaciones e interferencias durante los períodos de recolección de heces, se elaboró una rutina diaria para los caballos por medio de la inclusión de varias actividades que se realizaron desde los períodos de acostumbramiento. Dicho horario incluía las horas para proporcionarles el alimento, la recolección de las heces y la salida a caminar de los equinos.

La recolección de heces fue manual con un recipiente específico para cada uno de los tratamientos. Durante los días de adaptación, las heces fueron recolectadas individualmente y pesadas en los recipientes para cada tratamiento. Una vez recolectada dicha información, las heces fueron desechadas. Para los días de recolección, éstas se recolectaban de manera individual, se pesaban, embolsaban y rotulaban para cada uno de los caballos con su respectiva hora de recolección y las muestras compuestas se realizaban al día siguiente. Dichas muestras compuestas eran realizadas a partir de las heces recolectadas a lo largo del día. Debido a que se contaba con registro de los pesos de cada una de las excreciones, se seleccionaba la masa más pequeña registrada y se proseguía a tomar de cada una de las otras muestras de heces recolectadas la misma cantidad para evitar mayor presencia de una muestra que de otra (uniformización). Las 
muestras individuales del periodo de recolección y las compuestas se almacenaron en un recipiente aislante de calor protegidas del sol y de altas temperaturas. Durante todo momento en el que se manipularon las heces, se procuró minimizar el riesgo de contaminación por agentes externos como la cama de las cuadras, residuos de alimento o cualquier otro material que pudiera alterar la composición de las heces a nivel de laboratorio. En el caso en el que las heces tuvieran residuos de la cama de los respectivos establos, se les eliminó con la ayuda de una brocha.

Los análisis de composición nutricional comprendieron la materia seca (MS), proteína cruda (PC), extracto etéreo (EE) y cenizas (CT) de acuerdo a los procedimientos de AOAC (2010). Con respecto a la fibra detergente neutro (FDN), fibra ácida detergente (FAD) y lignina, se utilizó la metodología de Van Soest, Robertson y Lewis (1991). El contenido de carbohidratos no fibrosos (CNF) se estimó mediante la ecuación propuesta por Mertens (1988). Asimismo se determinó el contenido de cenizas insolubles en ácido clorhídrico 2 Normal $(2 \mathrm{~N} \mathrm{HCl})$ de acuerdo a la metodología de Van Keulen y Young (1977).

La digestibilidad aparente de los nutrientes se determinó por medio de la siguiente ecuación:

$$
\text { Digestibilidad }=100-100 * \frac{\% \text { indicador en alimento }}{\% \text { indicador en heces }} * \frac{\% \text { nutriente en heces }}{\% \text { nutriente en alimento }}
$$

Para la determinación de cenizas insolubles en ácido, se pesó la muestra y se incineró en una primera etapa. Una vez incineradas, las muestras se sometieron a una digestión en $2 \mathrm{~N} \mathrm{HCl}$ y se filtró en un embudo Buchner con papel filtro libre de cenizas. Se debió garantizar que todo el material incinerado de la muestra fuera filtrado y recolectado en el papel filtro para evitar pérdidas de material. Una vez filtradas las muestras, se traspasó a su respectivo crisol y se sometió a una segunda incineración, después de la cual, se puso en desecadores y se pesó para obtener los datos necesarios para calcular la concentración de cenizas insolubles en ácido. 
El análisis estadístico referente a la digestibilidad aparente y consumo fue realizado utilizando el programa SAS (2000) por medio del siguiente modelo:

$$
Y_{i}=\mu+T_{j}+P_{k}+A_{l}++e_{i j k l}
$$

$\mu=$ media de las variables estudiadas

$\mathrm{T}=\mathrm{j}$-esimo efecto de los tratamientos $(0,15,30$ y $45 \%)$

$\mathrm{P}=\mathrm{k}$-ésimo efecto de los cuatro períodos evaluados (columna; 1, 2, 3, 4)

$A$ = l-ésimo efecto del animal (hilera; 1, 2, 3, 4)

$\mathrm{e}_{\mathrm{ijk} \mathrm{l}}=$ error experimental.

La comparación entre tratamientos se realizó con la prueba de Duncan con el objetivo de encontrar diferencias significativas $(p \leq 0,05)$ entre los tratamientos.

\section{RESULTADOS Y DISCUSIÓN}

En el Cuadro 5, se muestra el consumo promedio de forraje Estrella africana ( $\mathrm{kg}$ MS animal'día) para los caballos del estudio. Se estimó un consumo promedio de 4,83kg lo que representa un aporte del $0,98 \%$ PV (73\% en la ración total) lo que indica que la dieta suministraba aportes adecuados de fibra para el animal.

Cuadro 5. Consumo promedio de Estrella Africana (kg MS/animal/día).

\begin{tabular}{ccccc}
\hline & \multicolumn{4}{c}{ Tratamiento (\%) } \\
\cline { 2 - 5 } Periodo & 0(control) & $\mathbf{1 5}$ & $\mathbf{3 0}$ & $\mathbf{4 5}$ \\
\hline 1 & 4,70 & 4,20 & 4,80 & 5,40 \\
2 & 5,10 & 5,00 & 4,20 & 4,80 \\
3 & 4,60 & 5,25 & 5,15 & 4,35 \\
4 & 4,10 & 4,70 & 5,40 & 5,30 \\
Promedio & 4,60 & 4,80 & 4,90 & 5,00 \\
\hline
\end{tabular}


Los consumos diarios de Stylosanthes para los tratamientos 15, 30 y 45\%, fueron de 261 , 522 y 780 gramos de materia seca, respectivamente. Si bien este ingrediente contiene cantidades importantes de fibra (44,6\% FND) el aporte físico de este nutriente se reduce debido al proceso industrial durante el peletizado. Considerando ambas fuentes forrajeras, el aporte total del componente forrajero representó un 1,06\% PV (81,5\% ración total) lo cual es inferior a lo recomendado por las tablas del NRC (2007) del 1,5\%PV, sin embargo, los animales durante el periodo experimental no presentaron síntomas de deficiencia tales como mala consistencia de heces o cólicos. En el presente experimento los consumos promedio de FDN fueron de $3,76 \mathrm{~kg}$ animal/día lo cual se asociaría a los altos contenidos de FDN de los forrajes tropicales. El consumo diario de alimento balanceado fue constante a lo largo de los periodos de acuerdo a los tratamientos mostrando valores de $1,74,1,48,1,22$ y 0,96 kilogramos de materia seca respectivamente para los tratamientos $0 \%, 15 \%, 30 \%$ y $45 \%$.

El consumo promedio de nutrientes para cada tratamiento se presenta en el Cuadro 6, donde se denota que conforme se va sustituyendo el alimento balanceado con los pellets de Stylosanthes, se presenta un aumento general en el consumo de MS. El consumo de PC tiende a disminuir hasta el tratamiento de $30 \%$ de sustitución, luego del cual el consumo no es estadísticamente diferente que el obtenido en el tratamiento control. El consumo de FAD y FND tendieron a aumentar hasta el tratamiento de $30 \%$, valores superiores como la sustitución del $45 \%$ del alimento balanceado mostraron consumos similares a los del tratamiento control. El consumo de CNF disminuyó de forma significativa conforme se aumentó la proporción de pellets de Stylosanthes en la ración mientras que el consumo de EE fue similar entre los 4 tratamientos. Es importante mencionar que de todos los nutrientes evaluados en las dietas, solamente la PC y el EE mostraron diferencias significativas entre los tratamientos y periodos respectivamente, mientras que los CNF presentaron diferencias significativas entre los tratamientos únicamente (Cuadro 6). 
20

Nutrición Animal Tropical

Cuadro 6. Consumos promedio $(\mathrm{kg})$ de materia seca, proteína cruda, fibra ácido detergente, fibra neutro detergente, extracto etéreo y carbohidratos no fibrosos para cada tratamiento.

\begin{tabular}{|c|c|c|c|c|c|c|c|c|}
\hline \multirow[b]{2}{*}{ Nutriente } & \multicolumn{4}{|c|}{ Tratamiento (\%) } & \multirow[t]{2}{*}{ DEM $^{*}$} & \multicolumn{3}{|c|}{ Probabilidad } \\
\hline & 0(control) & 15 & 30 & 45 & & Trat.** & Ani. ${ }^{\star \star \star}$ & Per..$^{\star \star \star \star}$ \\
\hline MS & 6,52 & 6,52 & 6,58 & 6,62 & 0,44 & 0,8910 & 0,9750 & 0,9950 \\
\hline PC & $0,84^{\mathrm{a}}$ & $0,73^{\mathrm{ab}}$ & $0,68^{b}$ & $0,85^{a}$ & 0,09 & 0,5230 & 0,9680 & 0,0420 \\
\hline FAD & 2,11 & 2,24 & 2,31 & 2,15 & 0,23 & 0,3570 & 0,9760 & 0,7040 \\
\hline FND & 3,66 & 3,80 & 3,86 & 3,73 & 0,33 & 0,6400 & 0,9760 & 0,9270 \\
\hline EE & 0,19 & 0,18 & 0,17 & 0,19 & 0,03 & 0,0008 & 0,9690 & 0,1720 \\
\hline CNF & $1,41^{a}$ & $1,35^{a}$ & $1,28^{b c}$ & $1,21^{\mathrm{C}}$ & 0,09 & 0,0300 & 0,9200 & 0,9800 \\
\hline
\end{tabular}

*Desviación Estándar de la Media. ${ }^{* \star}$ Trat=Tratamiento. ${ }^{* \star *}$ Ani=Animal. ${ }^{* * \star}$ Per=Periodo

Se determinó que la digestibilidad aparente de la MS, la PC y la FAD de la dieta no se alteraron significativamente mientras que para la FDN, los CNF y el EE se encontraron diferencias entre las medias de cada tratamiento debidas a la inclusión creciente de los pellets de Stylosanthes (Cuadro 7).

Cuadro 7. Digestibilidades aparente (\%) de los nutrientes en las dietas utilizadas.

\begin{tabular}{|c|c|c|c|c|c|c|c|c|}
\hline \multirow[b]{2}{*}{ Nutriente } & \multicolumn{4}{|c|}{ Tratamiento (\%) } & \multirow[t]{2}{*}{ DEM $^{*}$} & \multicolumn{3}{|c|}{ Probabilidad } \\
\hline & 0 (control) & 15 & 30 & 45 & & Trat. $^{* *}$ & Ani. ${ }^{* \star *}$ & 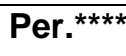 \\
\hline MS & 64,66 & 61,77 & 62,99 & 64,26 & 2,76 & 0,2400 & 0,1640 & 0,0700 \\
\hline PC & 68,88 & 65,66 & 66,94 & 69,57 & 2,74 & 0,182 & 0,2870 & 0,5480 \\
\hline FAD & 33,06 & 35,51 & 32,57 & 35,80 & 7,56 & 0,1501 & 0,0130 & 0,0001 \\
\hline FND & $46,46^{\mathrm{ab}}$ & $48,17^{\mathrm{a}}$ & $43,46^{\mathrm{b}}$ & $46,47^{\mathrm{ab}}$ & 5,43 & 0,1370 & 0,0520 & 0,0030 \\
\hline EE & $69,54^{\mathrm{b}}$ & $82,80^{a b}$ & $78,76^{\mathrm{ab}}$ & $83,67 a$ & 10,74 & 0,1300 & 0,2530 & 0,1120 \\
\hline CNF & $79,00^{\mathrm{ab}}$ & $65,00^{\mathrm{b}}$ & $80,00^{\mathrm{a}}$ & $68,00 \mathrm{~b}$ & 0,07 & 0,0002 & 0,8150 & 0,0170 \\
\hline
\end{tabular}

*Desviación Estándar de Media. ${ }^{* \star}$ Trat=Tratamiento. ${ }^{* \star *}$ Ani=Animal. ${ }^{* \star \star \star}$ Per=Periodo 


\section{CONCLUSIONES Y RECOMENDACIONES}

La sustitución hasta un $45 \%$ del alimento balanceado por pellets de Stylosanthes no afectó significativamente la digestibilidad aparente de la MS, PC y FAD de la ración total. Mientras que la digestibilidad de la FND, EE y CNF fueron alteradas por la sustitución del alimento balanceado por el forraje peletizado en estudio. El pellet de Stylosanthes no presentó problemas de palatabilidad con los niveles máximos utilizados en la presente investigación (0,900 kg. Animal/día). La sustitución del 15; 30 o 45\% del alimento balanceado por el pellet de Stylosanthes reduce los costos de suplementación en un 3,4; 6,9 y $10,3 \%$ respectivamente.

\section{IMPLICACIONES}

En relación a su composición nutricional los pellets de Stylosanthes pueden ser, en cierta medida, comparables con los de alfalfa, y por lo tanto se pueden considerar en condiciones tropicales como una fuente alternativa a los pellets de forraje de alfalfa (Medicago sativa), sin embargo se debe investigar más sobre las edades de cosecha y el proceso de elaboración. Además es recomendable llevar a cabo pruebas de comportamiento en equinos con dicho material.

\section{AGRADECIMIENTOS}

A la empresa Fudesemillas, Costa Rica por proporcionar el material para llevar a cabo la investigación. A la fábrica de Alimentos Balanceados de la Cooperativa Dos Pinos por su colaboración en la realización de análisis; al Centro de Investigaciones Nutrición Animal y sus colaboradores por toda la ayuda proporcionada. 


\section{LITERATURA CITADA}

AOAC INTERNATIONAL. 2010. Official Methods of analysis $18^{\text {th }}$ Edition. George Latimer, USA.

COOK, B.G., PENGELLY, B.C., BROWN, S.D., DONNELLY, J.L., EAGLES, D.A., FRANCO, M.A., HANSON, J., MULLEN, B.F., PARTRIDGE, I.J., PETERS, M. AND SCHULTZE-KRAFT, R. 2005. Tropical Forages: an interactive selection tool., [CDROM], CSIRO, DPI\&F(QId), CIAT and ILRI, Brisbane, Australia.

EMBRAPA. 2000. Estilosantes Campo Grande. http://www.cnpgc.embrapa.br/publicacoes/divulga/GCD38.html// (consultado 13 abril 2012).

LAWRENCE, L. 1995. Equine feeding management: the how \& when of feeding horses. Cooperative Extension Service ASC-143. University of Kentucky.

MERTENS, D.R. 1988. Balancing carbohydrates in dairy rations. Proc. Large Herd Dairy Mgmt. Conf. Dept. Animal Sci.,Cornell Univ.Ithaca,NY..

NATIONAL RESEARCH COUNCIL (NRC). 2007. Nutrient requirements of horses. Sixth Revised Edition. National Academies Press, Estados Unidos.

PULIDO, R.G., ROMENY, A., ESCOBAR, A. 2003. Digestibilidad de avena entera y laminada al vapor en yeguas. Agro Sur 31 (2): 75-80.

STATISTICAL ANALYSIS SYSTEM (SAS). 2000. User's Guide Statistics. SAS Institute Inc. Cary, NC.

TEXEIRA, V.I., DUBEUX, JR.J.C.B., SANTOS, M.V.F., LIRA, JR.M de A., SILVA, H.M.S. 2010. Aspectos agronómicos y bromatológicos de leguminosas forrajeras al norte Brasileño. Archivos de Zootecnia 59 (226): 245-254. 
VALLIS, I., GARDENER, C.J. 1984. Nitrogen inputs into agricultural systems by Stylosanthes. In: H.M. Stace, L.A. Edye (eds) The biology and agronomy of Stylosanthes. Academic Press: Australia pp. 359-379.

VAN KEULEN, J., YOUNG, B.A. 1977. Evaluation of acid insoluble ash as a natural marker in ruminant digestibility studies. Journal of Animal Science 44:282.

VAN SOEST, P.J., ROBERTSON, J.B., LEWIS, B.A. 1991. Symposium: carbohydrate methodology, metabolism, and nutritional implications in dairy cattle. Methods for dietary fiber, neutral detergent fiber and non-starch polysaccharides in relation to animal nutrition. Journal of Dairy Science 74: 3583-3597

VEIZAGA, E.A., DA PAIXAO FILHO, J. L., SILVEIRA, J. E., SIMOES DE SOUSA, C., DE BRITO, N. N., TEIXEIRA R. 2010. Estilosanthes campo grande, una opción para aplicaciones en una agricultura sostenible. VII Encuentro de agricultura orgánica y sostenible. VI Asamblea continental del movimiento agroecológico Latinoamericano. La Habana, Cuba. 